\title{
The prognosis of hepatoid adenocarcinoma of the stomach: a propensity score-based analysis
}

Kai Zhou ${ }^{1 \dagger}$, Anqiang Wang ${ }^{1 \dagger}$, Sheng $\mathrm{Ao}^{2 \dagger}$, Jiahui Chen ${ }^{1}$, Ke Ji ${ }^{1}$, Qifei He${ }^{1}$, Xin Ji', Xiaojiang Wu', Ji Zhang ${ }^{1}$, Zhongwu $\mathrm{Li}^{3}$, Zhaode $\mathrm{Bu}^{1^{*}}$ and Jiafu $\mathrm{Ji}^{7^{*}}$ (D)

\begin{abstract}
Background: To investigate whether there is a distinct difference in prognosis between hepatoid adenocarcinoma of the stomach (HAS) and non-hepatoid adenocarcinoma of the stomach (non-HAS) and whether HAS can benefit from radical surgery.

Methods: We retrospectively reviewed 722 patients with non-HAS and 75 patients with HAS who underwent radical gastrectomy between 3 November 2009 and 17 December 2018. Propensity score matching (PSM) analysis was used to eliminate the bias among the patients in our study. The relationships between gastric cancer type and overall survival (OS) were evaluated by the Kaplan-Meier method and Cox regression.

Results: Our data demonstrate that there was no statistically significant difference in the OS between HAS and non-HAS $\{K-M, P=\log$ rank (Mantel-Cox), (before PSM P =0.397); (1:1 PSM P=0.345); (1:2 PSM P =0.195)\}. Moreover, there were no significant differences in the 1-, 2-, or 3-year survival rates between patients with non-HAS and patients with HAS (before propensity matching, after 1:1 propensity matching, and after 1:2 propensity matching).
\end{abstract}

Conclusion: HAS was generally considered to be an aggressive gastric neoplasm, but its prognosis may not be as unsatisfactory as previously believed.

Keywords: Hepatoid adenocarcinoma of the stomach, Non-hepatoid adenocarcinoma of the stomach, Overall survival, Prognosis

\section{Background}

Gastric carcinoma (GC) is not only the second most common cancer but also the third leading cause of death in China [1,2], which poses a great threat to people's health in China [3]. Although the incidence rate of GC has been declining steadily with the improvement of heath standards, nutrition levels and radical treatment of

\footnotetext{
* Correspondence: buzhaode@cjcrn.org; jijiafu@hsc.pku.edu.cn

${ }^{\dagger}$ Kai Zhou, Anqiang Wang and Sheng Ao contributed equally to this work. 'Department of Gastrointestinal Surgery, Key Laboratory of Carcinogenesis and Translational Research (Ministry of Education), Peking University Cancer Hospital \& Institute, No. 52 Fucheng Road, Haidian District, Beijing 100142, China

Full list of author information is available at the end of the article
}

Helicobacter pylori, the long-term survival is far from satisfactory [4-6]. Rare types of cancer without standard treatment modalities partly contribute to the adverse outcomes of GC. As a rare type of GC [7, 8], hepatoid adenocarcinoma of the stomach (HAS) is a special type of extrahepatic carcinoma characterized by the histological resemblance to hepatocellular carcinoma $[9,10]$.

In 1970, Bourreille first reported one case of $\alpha$ fetoprotein-producing gastric carcinoma with liver metastasis [11]. Later, Ishikura et al. named it "hepatoid adenocarcinoma of the stomach" for primary GC $[12,13]$. It was reported that this rare type of GC accounts for 0.38 to $1 \%$ of GC. In addition to similar

(c) The Author(s). 2020 Open Access This article is licensed under a Creative Commons Attribution 4.0 International License, which permits use, sharing, adaptation, distribution and reproduction in any medium or format, as long as you give appropriate credit to the original author(s) and the source, provide a link to the Creative Commons licence, and indicate if changes were made. The images or other third party material in this article are included in the article's Creative Commons licence, unless indicated otherwise in a credit line to the material. If material is not included in the article's Creative Commons licence and your intended use is not permitted by statutory regulation or exceeds the permitted use, you will need to obtain permission directly from the copyright holder. To view a copy of this licence, visit http://creativecommons.org/licenses/by/4.0/. The Creative Commons Public Domain Dedication waiver (http://creativecommons.org/publicdomain/zero/1.0/) applies to the data made available in this article, unless otherwise stated in a credit line to the data. 
clinical features, such as occurring mainly in elderly and male patients [7], HAS was found to be accompanied by a higher rate of lymph node and liver metastasis in comparison with GC [14, 15]. Additionally, more than $80 \%$ of HAS patients had elevated serum $\alpha$-fetoprotein (AFP) levels $[14,16]$. Considering the higher rate of metastasis, the prognosis of HAS has been widely reported to be inferior to that of nonHAS [17]. To the best of our knowledge, however, most studies have been limited to case reports or case series [18]. Therefore, a more systematic study with more cases is especially meaningful for the prognostic exploration of HAS.

In our study, to explore the prognosis of HAS and whether HAS can benefit from radical surgery, we conducted propensity score-based analyses on a larger number of patients with GC.

\section{Methods}

\section{Patients}

Patients of 797 who underwent radical surgical resection for gastric carcinoma at the Peking University Cancer Hospital between 3 November 2009 and 17 December 2018 were considered for inclusion in the study. Patients with GC were diagnosed by gastroscopy, biopsy and computed tomography. GC patients with sufficient clinicopathological information were included in our research. However, patients without radical surgery and who were diagnosed with non-adenocarcinoma were excluded. For advanced gastric cancer (including non-HAS and HAS), if there was no distant metastasis or invasion of surrounding organs, D2 lymphadenectomy is recommended, which is performed by experienced doctors.

We collected clinical information, including sex, age, tumor location, surgery type, and levels of carcinoembryonic antigen (CEA) and carbohydrate antigen 19-9 (CA199). Pathological features such as vascular invasion, TNM stage (American Joint Committee on Cancer (AJCC), 7th edition), immunohistochemistry results and neoadjuvant chemotherapy were also gathered. The basic clinical characteristics were listed in (Additional file 1: Table 1).

\section{The diagnose of patients}

Before surgery, pelvic and abdominal contrast-enhanced computed tomography (CT) was used to check patients' condition of local lymph nodes and surrounding organs and determine the lesion area of GC, while gastroscopy biopsy was performed to determine the pathological type at the same time. The gastroscopy biopsy and (or) surgical specimens of HAS both have different percentages of HAS cell components. Once the pre-operative and postoperative specimens were found with adenocarcinoma, hepatocellular carcinoma or the sole hepatocyte-like regions in morphology, which would be added to examine several immune-histochemical markers, such as AFP [19], Glypican-3(GPC-3), SALL4 and Hap-Par 1 [7, 20]. If the immunohistochemical marker AFP was positive, we preliminarily considered the diagnosis of a patient's disease as HAS. Under these circumstances, most lesions contained aberrant hepatocellular differentiation [21]. The neoplastic tissue of HAS had other than a trabecular pattern with a round to ovoid nuclei, some existed intranuclear pseudoinclusions, and some with large cells of eosinophilic cytoplasm as well as prominent nucleoli [14]. The gastroscopy biopsy and (or) surgical specimens of HAS had different HAS cell component percentages [7]. Therefore, the definitive diagnosis of HAS depended on the histomorphological features plus immunophenotypical evidence [19].

Two pathologists assessed AFP staining based on the percentage of stained celled and staining density. The percentage score of stained cells was divided into three groups: 0 for unstained cells, 1 for $1-50 \%$ stained cells, and 2 for $51-100 \%$ stained cells. The staining density ranged from 0 to 3: 0 for intense, 1 for mild, 2 for moderate, and 3 for staining [7].

\section{Follow-up visits}

We completed the follow-up at our hospital by telephone. The status of all patients was assessed every 3 to 6 months during follow-up. We routinely checked chest and abdominal computed tomography (CT), tumor markers (CEA, CA199, carbohydrate antigen 242(CA242), carbohydrate antigen 724 (CA724)). Liver-specific contrast-enhanced Magnetic Resonance Imaging (MRI) (the result of this check was presented as multiple lesions in the liver, which was typically characterized by the bovine eye sign), positron emission tomography-computed tomography (PET-CT) and other examinations were considered to be checked according to the special situations of patients. Overall survival (OS) time was recorded during the time from the date of surgery to the date of death of cancer or the date of the last follow-up. The follow-up period lasted three years.

\section{Propensity score analysis (PSM)}

To accurately analyzed the prognosis of HAS, we used propensity score matching to balance out the bias between HAS and non-HAS patients. The propensity score of all patients was determined by using the chi-square and Mann-Whitney U tests (Table 1). According to a 0.02 caliper width, one-to-one nearest-neighbour matching was carried out. One-totwo nearest-neighbour matching was performed with a 0.05 caliper width. 
Table 1 Clinicopatholodical characteristics of patients with HAS and Non-HAS treated with radical gastrectomy

\begin{tabular}{|c|c|c|c|c|c|c|c|c|c|}
\hline \multirow[t]{4}{*}{ Factors } & \multicolumn{3}{|c|}{ Before propensity matching } & \multicolumn{3}{|c|}{ After 1:1 propensity matching } & \multicolumn{3}{|c|}{ After 1:2 propensity matching } \\
\hline & \multirow{2}{*}{$\begin{array}{l}\text { Non-HAS } \\
(n=711)\end{array}$} & \multirow{2}{*}{$\begin{array}{l}\text { HAS } \\
(n=73)\end{array}$} & \multirow{3}{*}{$\begin{array}{l}P \\
\text { value* }\end{array}$} & \multirow{2}{*}{$\begin{array}{l}\text { Non-HAS } \\
n=72\end{array}$} & \multirow{2}{*}{$\begin{array}{l}\text { HAS } \\
N=72\end{array}$} & \multirow{3}{*}{$\begin{array}{l}P \\
\text { value }\end{array}$} & \multirow{2}{*}{$\begin{array}{l}\text { Non-HAS } \\
n=110\end{array}$} & \multirow{3}{*}{$\begin{array}{l}\text { HAS } \\
n=55 \\
\text { No. (\%) }\end{array}$} & \multirow{3}{*}{$\begin{array}{l}P \\
\text { value }\end{array}$} \\
\hline & & & & & & & & & \\
\hline & No. (\%) & No. (\%) & & No. (\%) & No. (\%) & & No. (\%) & & \\
\hline$\overline{\operatorname{Sex}(M / F)}$ & $509 / 202$ & $60 / 13$ & 0.053 & $60 / 12$ & $59 / 13$ & 0.826 & $87 / 23$ & $44 / 11$ & 0.892 \\
\hline Age (median) $(y r))^{\#}$ & $59(24-84)$ & $58(26-76)$ & 0.720 & $62(31-81)$ & $58(26-76)$ & 0.155 & $58(36-80)$ & $60(26-76)$ & 0.136 \\
\hline$<45$ & $78(11.0)$ & $7(9.6)$ & & $3(4.2)$ & $7(9.7)$ & & $12(10.9)$ & $5(9.1)$ & \\
\hline $60>$ age $\geq 45$ & $278(39.1)$ & $32(43.8)$ & & $26(36.1)$ & $31(43.1)$ & & $50(45.5)$ & $22(40.0)$ & \\
\hline$\geq 60$ & $355(49.9)$ & $34(46.6)$ & & $43(59.7)$ & $34(47.2)$ & & $48(43.6)$ & $28(50.9)$ & \\
\hline Location $^{\text {a }}$ & & & 0.364 & & & 0.640 & & & 0.785 \\
\hline$U$ & $217(30.5)$ & $25(34.2)$ & & $19(26.4)$ & $24(33.3)$ & & $39(35.5)$ & $19(34.5)$ & \\
\hline M & $126(17.7)$ & $9(12.3)$ & & $11(15.3)$ & $9(12.5)$ & & $11(10.0)$ & $7(12.7)$ & \\
\hline L & $360(50.6)$ & $39(53.4)$ & & $42(58.3)$ & $39(54.2)$ & & $59(53.6)$ & $29(52.7)$ & \\
\hline $\mathrm{T}$ & $8(1.1)$ & $0(0.0)$ & & $0(0.0)$ & $0(0.0)$ & & $1(0.9)$ & $0(0.0)$ & \\
\hline Surgery type & & & 0.584 & & & 1.000 & & & 0.445 \\
\hline PG & $9(1.3)$ & $2(2.7)$ & & $0(0.0)$ & $1(0.7)$ & & $1(0.9)$ & $2(3.6)$ & \\
\hline DG & $350(49.2)$ & 39 (53.4) & & $42(58.3)$ & $40(56.9)$ & & $55(50.0)$ & $30(54.5)$ & \\
\hline TG & $349(49.1)$ & $32(43.8)$ & & $30(41.7)$ & $31(42.4)$ & & $53(48.2)$ & $23(41.8)$ & \\
\hline TGC & $3(0.4)$ & $0(0.0)$ & & $0(0.0)$ & $0(0.0)$ & & $1(0.9)$ & $0(0.0)$ & \\
\hline Vascular invasion & & & 0.328 & & & 0.074 & & & 0.315 \\
\hline no & $325(45.7)$ & 29 (39.7) & & $18(25.0)$ & 28 (38.9) & & $49(44.5)$ & $20(36.4)$ & \\
\hline yes & $386(54.3)$ & $44(60.3)$ & & $54(75.0)$ & $44(61.1)$ & & $61(55.5)$ & 35 (63.6) & \\
\hline $\mathrm{T}$ & & & 0.004 & & & 0.051 & & & 0.990 \\
\hline Tis, T0, T1, T2 & $171(24.0)$ & $21(28.8)$ & & $18(25.0)$ & $20(27.8)$ & & $34(30.9)$ & 17 (30.9) & \\
\hline $\mathrm{T} 3$ & 260 (36.6) & $39(53.4)$ & & $26(36.1)$ & $37(51.4)$ & & $51(46.4)$ & $26(47.3)$ & \\
\hline $\mathrm{T} 4$ & $280(39.4)$ & $13(17.8)$ & & $28(38.9)$ & $15(20.8)$ & & $25(22.7)$ & $12(21.8)$ & \\
\hline N & & & 0.180 & & & 0.182 & & & 0.566 \\
\hline No & $221(31.1)$ & $11(15.1)$ & & $12(16.7)$ & $11(15.3)$ & & $29(26.4)$ & $11(20.0)$ & \\
\hline N1 & $154(21.7)$ & $23(31.5)$ & & $18(25.0)$ & $23(31.9)$ & & $24(21.8)$ & $17(30.9)$ & \\
\hline N2 & $143(20.1)$ & $22(30.1)$ & & $14(19.4)$ & $23(31.9)$ & & $30(27.3)$ & $13(23.6)$ & \\
\hline N3 & $293(27.1)$ & $17(23.3)$ & & $28(38.9)$ & $15(20.8)$ & & $27(24.5)$ & $14(25.5)$ & \\
\hline M & & & & & & 1.00 & & & 1.000 \\
\hline MO & $711(100)$ & 73 (100) & & $69(95.8)$ & $70(97.2)$ & & 109 (99.1) & $54(98.2)$ & \\
\hline M1 & 0 & 0 & & $3(4.2)$ & $2(2.8)$ & & $1(0.9)$ & $1(1.8)$ & \\
\hline EGFR & & & $<0.001$ & & & 0.940 & & & 0.695 \\
\hline- & $64(9.0)$ & $2(2.7)$ & & $1(1.4)$ & $2(2.8)$ & & $6(5.5)$ & $2(3.6)$ & \\
\hline+ & $259(36.4)$ & $6(8.2)$ & & $16(22.2)$ & $7(9.7)$ & & $10(9.1)$ & $7(12.7)$ & \\
\hline++ & $195(27.4)$ & $36(49.3)$ & & $23(31.9)$ & $37(51.4)$ & & $46(41.8)$ & $26(47.3)$ & \\
\hline+++ & $193(27.1)$ & $29(39.7)$ & & $32(44.4)$ & $26(36.1)$ & & $48(43.6)$ & $20(36.4)$ & \\
\hline Ki-67 & & & 0.003 & & & 0.648 & & & 0.741 \\
\hline $0-25 \%$ & $65(9.1)$ & $5(6.8)$ & & $3(4.2)$ & $5(6.9)$ & & $10(9.1)$ & $5(9.1)$ & \\
\hline $26-50 \%$ & 168 (23.6) & $5(6.8)$ & & $10(13.9)$ & $6(8.3)$ & & $12(10.9)$ & $6(10.9)$ & \\
\hline $51-75 \%$ & $208(29.3)$ & $25(34.2)$ & & $18(25.0)$ & $24(33.3)$ & & 41 (37.3) & $16(29.1)$ & \\
\hline 76-100\% & $270(38.0)$ & $38(52.1)$ & & $41(56.9)$ & $37(51.4)$ & & $47(42.7)$ & $28(50.9)$ & \\
\hline CEA (ng/ml) & & & $<0.001$ & & & 0.384 & & & 0.266 \\
\hline
\end{tabular}


Table 1 Clinicopatholodical characteristics of patients with HAS and Non-HAS treated with radical gastrectomy (Continued)

\begin{tabular}{|c|c|c|c|c|c|c|c|c|c|}
\hline \multirow[t]{4}{*}{ Factors } & \multicolumn{3}{|c|}{ Before propensity matching } & \multicolumn{3}{|c|}{ After 1:1 propensity matching } & \multicolumn{3}{|c|}{ After 1:2 propensity matching } \\
\hline & \multirow{2}{*}{$\begin{array}{l}\text { Non-HAS } \\
(n=711)\end{array}$} & \multirow{2}{*}{$\begin{array}{l}\text { HAS } \\
(n=73)\end{array}$} & \multirow{3}{*}{$\begin{array}{l}\text { P } \\
\text { value* }\end{array}$} & \multirow{2}{*}{$\begin{array}{l}\text { Non-HAS } \\
n=72\end{array}$} & \multirow{2}{*}{$\begin{array}{l}\text { HAS } \\
N=72\end{array}$} & \multirow{3}{*}{$\begin{array}{l}P \\
\text { value }\end{array}$} & \multirow{3}{*}{$\begin{array}{l}\text { Non-HAS } \\
n=110 \\
\text { No. (\%) }\end{array}$} & \multirow{3}{*}{$\begin{array}{l}\text { HAS } \\
n=55 \\
\text { No. (\%) }\end{array}$} & \multirow{3}{*}{$\begin{array}{l}\mathrm{P} \\
\text { value }\end{array}$} \\
\hline & & & & & & & & & \\
\hline & No. (\%) & No. (\%) & & No. (\%) & No. (\%) & & & & \\
\hline$\leq 5$ & $575(80.9)$ & $45(61.6)$ & & $49(68.1)$ & $44(61.1)$ & & $77(70.0)$ & $43(78.2)$ & \\
\hline$>5$ & $136(19.1)$ & $28(38.4)$ & & $23(31.9)$ & $28(38.9)$ & & $33(30.0)$ & $12(21.8)$ & \\
\hline CA199 (u/ml) & & & 0.026 & & & 0.347 & & & 0.716 \\
\hline$\leq 37$ & $604(85.0)$ & $69(94.5)$ & & $65(90.3)$ & $68(94.4)$ & & $105(95.5)$ & $51(92.7)$ & \\
\hline$>37$ & $107(15.0)$ & $4(5.5)$ & & $7(9.7)$ & $4(5.6)$ & & $5(4.5)$ & $4(7.3)$ & \\
\hline Her-2 & & & 0.012 & & & 0.962 & & & 0.883 \\
\hline$-/+$ & $533(75.0)$ & $43(58.9)$ & & $43(59.7)$ & $43(59.7)$ & & $74(67.3)$ & $35(63.6)$ & \\
\hline+++ & $54(7.6)$ & $10(13.7)$ & & $10(13.9)$ & $9(12.5)$ & & $10(9.1)$ & $6(10.9)$ & \\
\hline++ & $124(17.4)$ & $20(27.4)$ & & $19(26.4)$ & $20(27.8)$ & & $26(23.6)$ & $14(25.5)$ & \\
\hline neoadjuvant chemotherapy & & & 0.005 & & & 0.441 & & & 0.880 \\
\hline no & $628(88.3)$ & $56(76.7)$ & & $52(72.2)$ & $56(77.8)$ & & $93(84.5)$ & 46 (83.6) & \\
\hline yes & $83(11.7)$ & $17(23.3)$ & & $20(27.8)$ & $16(22.2)$ & & 17 (15.5) & $9(16.4)$ & \\
\hline
\end{tabular}

$\mathrm{M}=$ male, $\mathrm{F}=$ female ${ }^{\mathrm{a}}$ Divide the major and minor curvature of the stomach into 3 equal parts, connect their corresponding points, can be divided into upper $1 / 3(\mathrm{U})$ middle $1 / 3(\mathrm{M})$, lower $1 / 3(\mathrm{~L})$ and the total stomach $(\mathrm{T}) \mathrm{TG}=$ total gastrectomy $\mathrm{DG}=$ distal gastrectomy $\mathrm{PG}=$ proximal gastrectomy

TGC=gastrectomy combined with visceral resection * categorical data were using the chi-square test $\left(\mathrm{X}^{2}\right.$ test), and continuous data were using the Mann-Whitney $\mathrm{U}$ test. \# median (range), and compared by non-parametric tests

\section{Statistical analysis}

Statistical analysis was conducted by using SPSS software version 23.0 (IBM, United States). The statistical significance of categorical data was assessed by using the chi-square test $\left(\mathrm{X}^{2}\right.$ test), and continuous data using the Mann-Whitney $\mathrm{U}$ test. We found that $\mathrm{T}$ stage (infiltration depth), EGFR, KI-76, the level of CEA and CA199, HER2 and neoadjuvant chemotherapy had statistically significant differences between HAS and non-HAS groups. According to the outcome and confounding variables to built a binary logistic regression analysis, and took stepwise regression. The variables of entering the model or having clinical significance were selected into the Covariates, elimination variables into the additional covariance of PSM. PSM effectively balanced the mixed bias of group HAS and non-HAS. We utilized the method of PSM to get two schemes of which the ratio were 1:1 and 1:2 (HAS: non-HAS), respectively. For the univariate analysis of OS, the Kaplan-Meier approach was used. For the multivariate analysis, the Cox regression was used. $\mathrm{P}<0.05$ was considered as the threshold of having statistical significance. In order to obtain a more vivid and beautiful survival analysis curve, KaplanMeier survival plots were made by using GraphPad Prism 5.

\section{Results}

\section{Study population}

From November 2009 to December 2018, 797 patients were enrolled in our research. A total of 722 (90.6\%) gastric adenocarcinoma cases (non-HAS) and 75 (9.4\%) HAS cases were detected by histological morphology and immunohistochemistry. However, 11 non-HAS and 2 HAS patients hand distant metastases (M1). To reduce bias, these patients were excluded from this evaluation. Through one-to-one nearest-neighbour matching with a 0.02 caliper width, 144 patients were included for analysis, with 72 HAS and non-HAS patients each. Through one-to-two nearest-neighbour matching with a 0.05 caliper width, 165 patients were included in our study, with 110 non-HAS patients and 55 HAS patients. (Fig. 1).

\section{Clinicopathological characteristics}

For the 797 patients, the two groups (HAS and nonHAS) were consistent in terms of sex, age, tumor location, surgery type, vascular invasion, and $\mathrm{N}$ (lymph node metastasis) and $M$ stage (distant metastasis). Nevertheless, the two groups were differentially distributed in terms of $\mathrm{T}$ stage, EGFR, KI-67, CEA, CA199, HER-2 and neoadjuvant chemotherapy. Oneto-one and one-to-two nearest-neighbour matching were used to generate 144 and 165 patients from the two groups, respectively. They showed no significant bias in clinicopathological characteristics. (Additional file 1: Table 1).

Survival among all patients and propensity-matched pairs In our analysis, we found that OS was not significantly different between the HAS group and the non-HAS group (Fig. 2). The median follow-up time of the pre- 


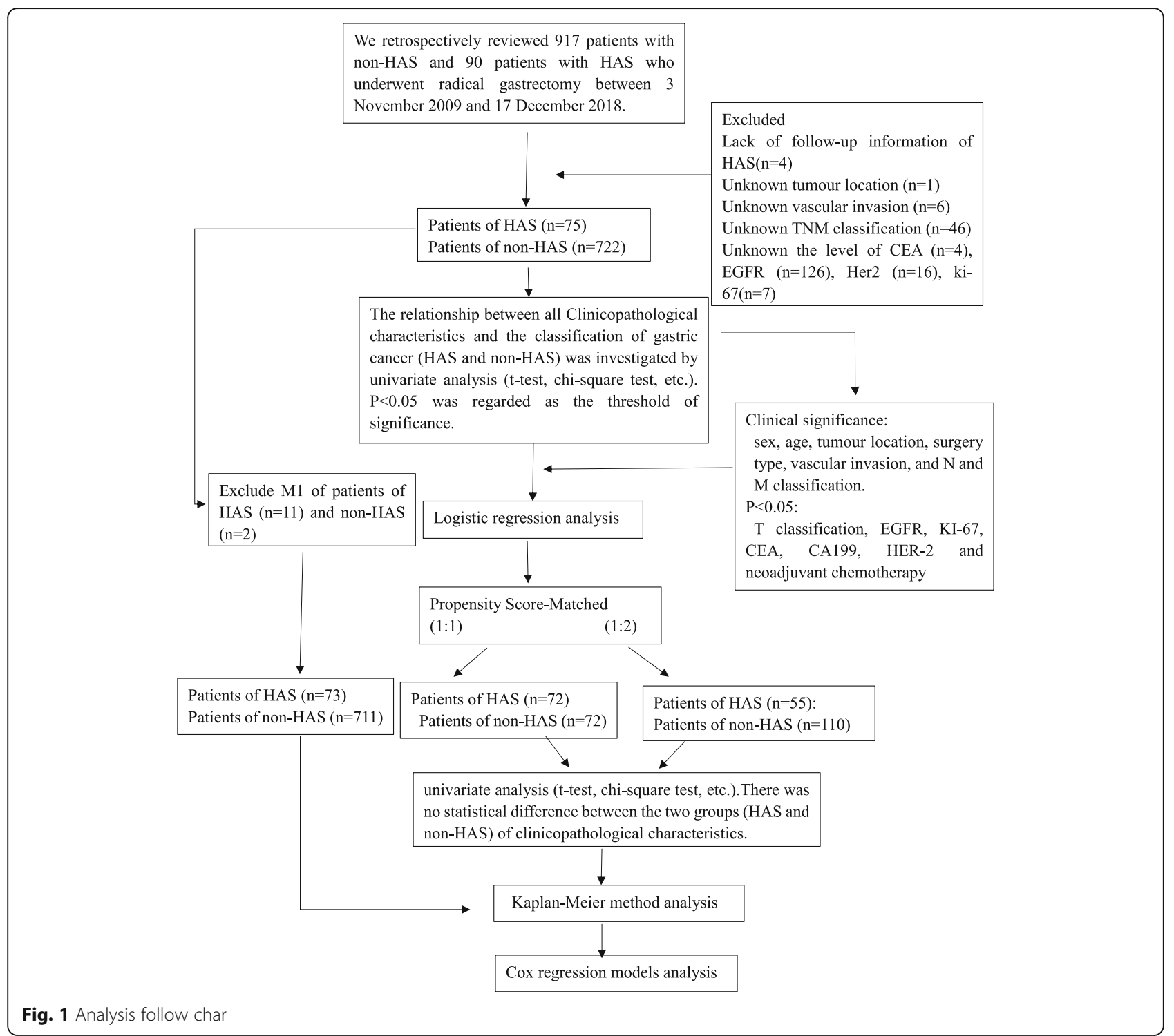

PSM cohort was 22.0 months (rang $=0$ to 97 months). The median follow-up time was 15.0 months (rang $=0$ to 97 months) after 1:1 PSM. The median follow-up time was 21.0 months (range $=0$ to 97 months) after 1:2 PSM. Among the 784 patients (13 patients with distant metastasis were excluded from 797 patients) in our study, the 1-, 2-, and 3-year survival rates of non-HAS patients were $92.6,81.1$, and $75.0 \%$, and those of HAS patients were $87.9,86.2$, and $82.6 \%$, respectively. Among the oneto-one nearest-neighbour matched pairs of patients, the 1-, 2-, and 3-year survival rates of non-HAS patients were $94.4,86.5$, and $82.3 \%$, and those of HAS patients were $92.9,86.3$ and $84.5 \%$, respectively. Among one-totwo nearest-neighbour matched pairs of patients, the 1-, 2-, and 3-year survival rates of non-HAS patients were 98.1, 98.1, and 96.9\%, and those of HAS patients were 90.3, 83.9 and $79.9 \%$, respectively.

\section{Risk factors for prognosis}

Among the 784 patients, univariate analysis showed that the tumour location, surgery type, vascular invasion, $\mathrm{T}$ and $\mathrm{N}$ stage, the levels of CEA and CA19-9, EGFR expression and neoadjuvant chemotherapy were significantly associated with OS. Among the one-to-one nearest-neighbour matched pairs of patients, $\mathrm{T}$ and $\mathrm{M}$ stage, EGFR expression and neoadjuvant chemotherapy were found to be significantly related to OS. Among the one-to-two propensity-matched pairs of patients, $\mathrm{T}$ and $M$ stage, level of CEA and EGFR expression were significantly associated with OS (Table 2).

Among the 784 patients, multivariate analysis identified prognostic factors including $\mathrm{T}$ and $\mathrm{N}$ stage, EGFR and neoadjuvant chemotherapy. There was no statistical difference of OS between HAS and nonHAS by using multivariable Cox regression models 

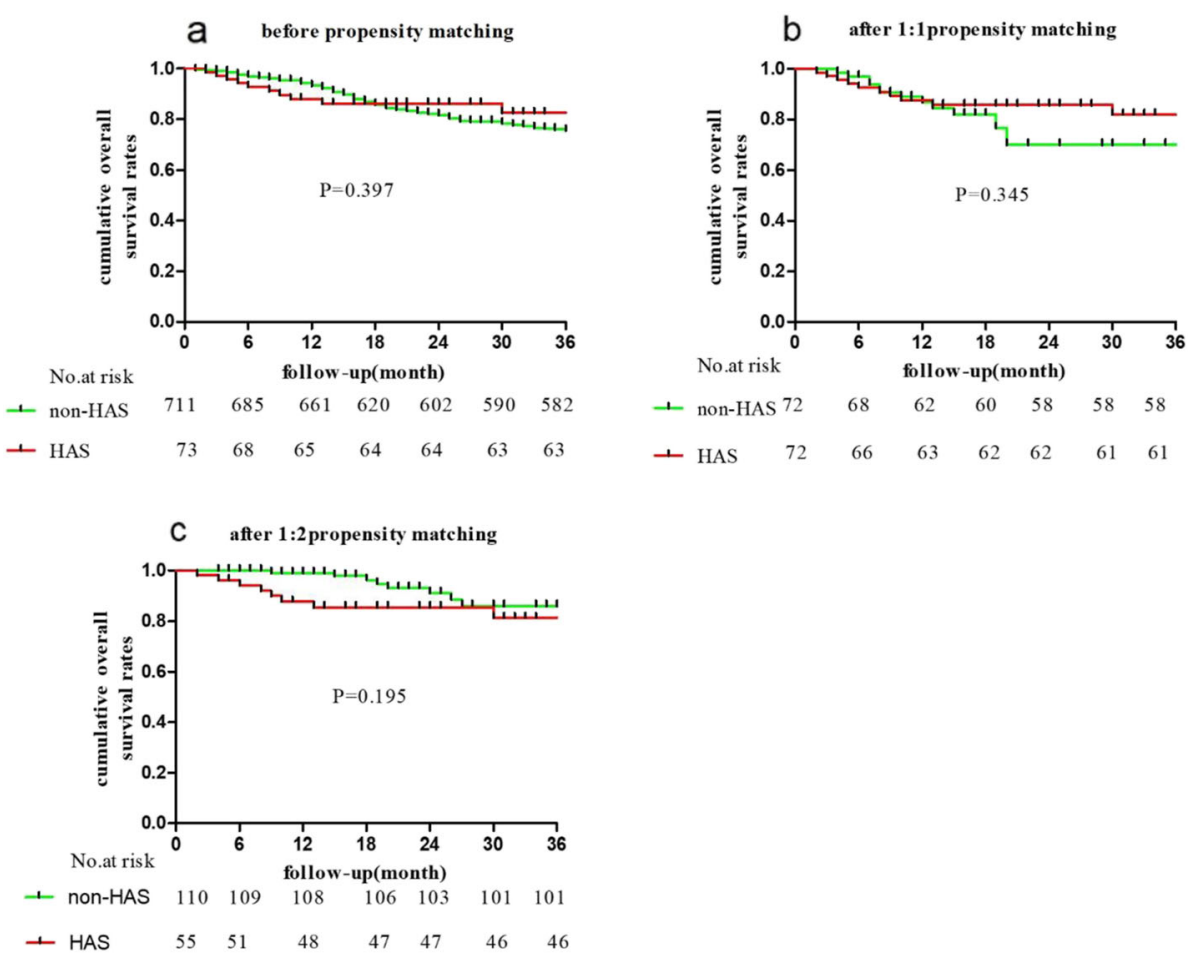

Fig. 2 Kaplan-Meier survival plots were made by using GraphPad Prism 5

given the following covariance: age, tumor location, surgery type, vascular invasion, $\mathrm{T}$ and $\mathrm{N}$ stage, the level of CEA and CA199, EGFR and neoadjuvant chemotherapy. $(\mathrm{P}=0.619)$ (Table 3a). Among the oneto-one nearest-neighbour matched pairs of patients, the univariate analysis identified some factors significantly related to OS, including the $\mathrm{T}$ stage, $\mathrm{M}$ stage, the level of CEA, EGFR and neoadjuvant chemotherapy. There was no statistical difference of OS between HAS and non-HAS by using multivariable Cox

Table 2 Univariate analyses of OS used the Kaplan-Meier approach

\begin{tabular}{llll}
\hline Factors $(k-m)$ & Before propensity matching $p$ value* & After 1:1 propensity matching $p$ value & $\begin{array}{l}\text { After 1:2 propensity matching } p \text { value } \\
\text { OS }\end{array}$ \\
\hline GC types $^{\mathrm{a}}$ & OS & 0.345 & 0.19 \\
Age & 0.410 & 0.345 & 0.446 \\
Sex & 0.368 & 0.277 & 0.322 \\
Location & 0.982 & 0.584 & 0.555 \\
Surgery type & 0.001 & 0.903 & 0.471 \\
Vascular invasion & $<0.001$ & 0.530 & 0.101 \\
T & $<0.001$ & 0.120 & 0.013 \\
N & $<0.001$ & 0.001 & 0.431 \\
M & $<0.001$ & 0.201 & $<0.001$ \\
CEA & - & $<0.001$ & $<0.002$ \\
CA199 & 0.006 & 0.066 & 0.312 \\
EGFR & $<0.001$ & 0.552 & 0.007 \\
HER2 & $<0.001$ & $<0.001$ & 0.644 \\
KI-67 & 0.380 & 0.397 & 0.258 \\
Neoadjuvant chemotherapy & 0.002 & 0.067 & 0.080 \\
\hline
\end{tabular}

a GC types: hepatoid adenocarcinoma of the stotmach and non-hepatoid adenocarcinoma of the stomach

*Log Rank (Mantel-Cox) 
Table 3 Multivariable survival analysis to identify factors predicting OS by using multivariable Cox regression models a Before propensity matching

\begin{tabular}{|c|c|c|c|c|c|c|c|}
\hline \multirow{2}{*}{\multicolumn{4}{|c|}{ a Before propensity matching }} & \multirow{3}{*}{$\begin{array}{l}\text { no } \\
\text { yes }\end{array}$} & \multirow{3}{*}{$\begin{array}{l}- \\
1.724\end{array}$} & \multirow{3}{*}{$1.123-2.646$} & \multirow{3}{*}{$\begin{array}{l}- \\
- \\
0.013\end{array}$} \\
\hline & & & & & & & \\
\hline Factor & $\mathrm{HR}$ & $95 \% \mathrm{Cl}$ & $P$ value & & & & \\
\hline \multicolumn{4}{|l|}{ GC type } & \multicolumn{3}{|c|}{ b After 1:1 propensity matching } & \\
\hline non-HAS & - & - & - & Factor & $\mathrm{HR}$ & $95 \% \mathrm{Cl}$ & $P$ \\
\hline HAS & 1.193 & $0.596-2.386$ & 0.619 & GC type & & & \\
\hline \multicolumn{3}{|l|}{ Age (yr) } & 0.463 & non-HAS & - & - & - \\
\hline$<45$ & - & - & - & HAS & 1.114 & $0.390-3.183$ & 0.841 \\
\hline $60>$ age $\geq 45$ & 1.113 & $0.621-1.993$ & 0.720 & Age (yr) & & & 0.158 \\
\hline$\geq 60$ & 1.335 & $0.752-2.372$ & 0.324 & $<45$ & - & - & - \\
\hline \multicolumn{3}{|l|}{ Location } & 0.978 & $60>$ age $\geq 45$ & 1.103 & $0.120-10.169$ & 0.931 \\
\hline U & - & - & - & $\geq 60$ & 2.716 & $0.322-22.934$ & 0.359 \\
\hline M & 1.000 & $0.628-1.594$ & 0.999 & Vascular invasion & & & \\
\hline L & 1.031 & $0.573-1.857$ & 0.918 & no & - & - & - \\
\hline $\mathrm{T}$ & 1.304 & $0.392-4.334$ & 0.665 & yes & 4.633 & $0.936-22.942$ & 0.060 \\
\hline \multicolumn{3}{|l|}{ Surgery type } & 0.152 & $\mathrm{~T}$ & & & 0.049 \\
\hline$P G$ & - & - & - & Tis,T0,T1,T2 & - & - & - \\
\hline DG & 1.096 & $0.137-8.782$ & 0.931 & $\mathrm{~T} 3$ & 3.779 & $0.674-21.186$ & 0.131 \\
\hline $\mathrm{TG}$ & 1.805 & $0.242-13.456$ & 0.564 & $\mathrm{~T} 4$ & 8.435 & $1.408-50.544$ & 0.020 \\
\hline TGC & 4.924 & $0.407-59.619$ & 0.210 & $\mathrm{~N}$ & & & 0.241 \\
\hline \multicolumn{4}{|l|}{ Vascular invasion } & No & - & - & - \\
\hline no & - & - & & N1 & 0.113 & $0.014-0.921$ & 0.042 \\
\hline yes & 1.145 & $0.771-1.701$ & 0.503 & N2 & 0.233 & $0.033-1.668$ & 0.147 \\
\hline \multicolumn{3}{|l|}{$\mathrm{T}$} & $<0.001$ & N3 & 0.198 & $0.024-1.659$ & 0.136 \\
\hline Tis,T0,T1,T2 & - & - & - & M & & & \\
\hline $\mathrm{T} 3$ & 1.930 & $0.939-3.967$ & 0.074 & Mo & - & - & - \\
\hline $\mathrm{T} 4$ & 3.518 & $1.756-7.050$ & $<0.001$ & M1 & 7.354 & $1.760-30.737$ & 0.006 \\
\hline \multicolumn{3}{|l|}{$\mathrm{N}$} & 0.001 & \multicolumn{4}{|l|}{ CEA (ng/ml) } \\
\hline NO & - & - & - & $\leq 5$ & & & \\
\hline N1 & 1.945 & $0.983-3.847$ & 0.056 & $>5$ & 3.123 & $1.276-7.643$ & 0.013 \\
\hline N2 & 2.133 & $1.070-4.252$ & 0.031 & CA199 (u/ml) & & & \\
\hline N3 & 3.579 & $1.839-6.966$ & $<0.001$ & $\leq 37$ & & & \\
\hline \multicolumn{4}{|l|}{ CEA (ng/ml) } & $>37$ & 4.275 & $0.759-24.071$ & 0.099 \\
\hline$\leq 5$ & - & - & - & EGFR & & & 0.030 \\
\hline$>5$ & 1.460 & $0.992-2.151$ & 0.055 & - & - & - & - \\
\hline \multicolumn{4}{|l|}{ CA199 (u/ml) } & + & 0.115 & $0.010-1.347$ & 0.085 \\
\hline$\leq 37$ & - & - & - & ++ & 0.028 & $0.002-0.375$ & 0.007 \\
\hline$>37$ & 1.514 & $0.998-2.297$ & 0.051 & +++ & 0.101 & $0.009-1.159$ & 0.066 \\
\hline \multicolumn{3}{|l|}{ EGFR } & 0.046 & \multicolumn{4}{|c|}{ Neoadjuvant chemotherapy } \\
\hline- & - & - & - & no & - & - & - \\
\hline+ & 1.342 & $0.788-2.286$ & 0.279 & yes & 3.816 & $1.339-10.878$ & 0.012 \\
\hline++ & 0.766 & $0.399-1.468$ & 0.422 & \multicolumn{4}{|c|}{ c After 1:2 propensity matching } \\
\hline+++ & 0.786 & $0.411-1.503$ & 0.467 & Factor & $\mathrm{HR}$ & $95 \% \mathrm{Cl}$ & $P$ \\
\hline \multicolumn{4}{|c|}{ Neoadjuvant chemotherapy } & GC type & & & \\
\hline
\end{tabular}

Table 3 Multivariable survival analysis to identify factors predicting OS by using multivariable Cox regression models a Before propensity matching (Continued)

no

yes 
Table 3 Multivariable survival analysis to identify factors predicting OS by using multivariable Cox regression models a Before propensity matching (Continued)

\begin{tabular}{|c|c|c|c|}
\hline non-HAS & - & - & - \\
\hline HAS & 2.579 & $0.839-7.925$ & 0.098 \\
\hline Age (yr) & & & 0.306 \\
\hline$<45$ & - & - & - \\
\hline $60>$ age $\geq 45$ & 5.503 & 0.159-190.915 & 0.346 \\
\hline$\geq 60$ & 9.580 & $0.304-301.867$ & 0.199 \\
\hline \multicolumn{4}{|c|}{ Vascular invasion } \\
\hline no & - & - & - \\
\hline yes & 2.597 & $0.472-14.281$ & 0.273 \\
\hline $\mathrm{T}$ & & & 0.207 \\
\hline Tis,T0,T1,T2 & - & - & - \\
\hline T3 & 5.591 & $0.775-40.367$ & 0.088 \\
\hline $\mathrm{T} 4$ & 6.032 & $0.732-49.721$ & 0.095 \\
\hline N & & & 0.640 \\
\hline No & - & - & - \\
\hline N1 & 0.637 & $0.072-5.636$ & 0.685 \\
\hline N2 & 0.355 & $0.036-3.515$ & 0.376 \\
\hline N3 & 0.912 & $0.111-7.474$ & 0.932 \\
\hline \multicolumn{4}{|l|}{ M } \\
\hline MO & - & - & - \\
\hline M1 & 51.522 & $2.359-1125.341$ & 0.012 \\
\hline CEA (ng/ml) & & & - \\
\hline$\leq 5$ & - & - & \\
\hline$>5$ & 8.116 & $2.294-28.719$ & 0.001 \\
\hline \multicolumn{4}{|l|}{ CA199 (u/ml) } \\
\hline \multicolumn{4}{|l|}{$\leq 37$} \\
\hline$>37$ & 0.000 & $0.000-$ & 0.983 \\
\hline EGFR & & & 0.214 \\
\hline- & - & - & - \\
\hline+ & 0.150 & $0.014-1.587$ & 0.115 \\
\hline++ & 0.094 & $0.009-0.929$ & 0.043 \\
\hline+++ & 0.136 & $0.019-0.996$ & 0.050 \\
\hline \multicolumn{4}{|c|}{ Neoadjuvant chemotherapy } \\
\hline no & - & - & - \\
\hline yes & 2.717 & $0.729-10.131$ & 0.137 \\
\hline
\end{tabular}

regression models given the following covariance: age, vascular invasion, TNM stage, the level of CEA and CA199, EGFR and neoadjuvant chemotherapy. ( $p=$ 0.841) (Table 3b). Among the one-to-two nearestneighbour matched pairs of patients, $M$ stage and the level of CEA associated with OS. There was no statistical difference of OS between HAS and non-HAS by using multivariable Cox regression models given the following covariates: age, vascular invasion, TNM stage, the level of CEA and CA199, EGFR and neoadjuvant chemotherapy. $(p=0.098)$ (Table 3c).

\section{Discussion}

HAS comprises polygonal cells arranged in solid or trabecular form, similar to that in hepatocellular carcinoma $[12,22]$. Many researchers supported that the common embryos of the stomach and liver originated from the foregut and may evolve through genetic progression and/or genetic differences [23, 24]. At present, there were two views on the prognosis of HAS and non-HAS. The majority of studies showed that HAS had a distinctly poorer prognosis than non-HAS $[9,10,25]$. However, a few reports suggested that HAS did not have a poorer prognosis. Although many researchers explored the clinical characteristics of HAS, there was still no unified standard for its diagnosis and treatment, and most of them were case reports [26]. In addition, owing to inadequate understanding of HAS and clinicians and pathologists did not pay much attention to it [21]. Therefore, it may be clinically difficult to draw a consistent conclusion of the prognostic impact of HAS. Certainly because of this, our study aimed to further elucidate whether HAS had a worse prognosis than nonHAS using a larger number of patients and whether HAS can benefit from radical surgery.

We used the propensity score matching method to eliminate the bias between HAS and non-HAS patients and then compared their prognoses. Our study showed that there was no significant difference in postoperative OS between HAS and non-HAS patients within 3 years after radical surgical resection, which is contrary to the majority of findings. The research from Liu et al. showed a significantly different prognosis between HAS and non-HAS [27]. The 1-, 3-, and 5-year survival rates of HAS and non-HAS (without AFP production) were 30,13 , and $9 \%$ and 95,57 , and $38 \%$, respectively [27]. In their research, the incidence of liver metastasis was $75.6 \%$ (34/45), including $8.9 \%$ synchronous and $73.2 \%$ (30/41) metachronous liver metastasis [27]. However, in the study by Cheon SH et al., among 10,259 patients diagnosed with gastric adenocarcinoma and 58 patients had live-only metastases after gastric resection [28]. Our research had seven HAS patients with postoperative liver metastasis (7/ 73). Therefore, we boldly speculated that the patients of HAS may had a higher risk of liver metastases [7, 29] than non-HAS, and the occurrence of liver metastasis contributed to the poorer prognosis of HAS, which was consistent with the findings of some reports [12, 30, 31]. It was worth mentioning that the prognosis of patients with higher serum levels of AFP was poorer than that of patients with lower serum levels of AFP $(<500 \mathrm{ng} / \mathrm{ml})$ [7]. Essentially, there remained no clear reasons for the poorer OS of HAS. Some researchers believe that HAS produced 
alpha-1 antitrypsin (AAT) and/or alpha-1 antichymotrypsin (ACT) and AFP, which enhanced invasiveness and affect immunosuppressive properties [12, 32, 33]. However, a few studies were consistent with ours. Wang et al., demonstrated that patients with HAS who underwent radical surgery had a 5-year survival rate of $41.1 \%$ [7]. Augustin $\mathrm{G}$ reported that a 72-year-old man was diagnosed with HAS underwent gastrectomy and splenectomy. He was still alive 24 months after surgery without distant metastasis [34]. Giustozzi G et al. reported that a HAS patient with radical surgery who underwent chemotherapy was still alive and disease-free (with a 52-month follow-up) [35]. Therefore, radical surgery and adjuvant chemotherapy may have a positive impact on the therapeutic effect $[36,37]$.

In our research, the univariate analysis suggested that both $\mathrm{T}$ and $\mathrm{M}$ stage were related to the OS of gastric adenocarcinoma in the groups of data before and after PSM, but the $\mathrm{N}$ stage had no significant relationship with prognosis in the data after propensity score matching. This finding may be attributed to the limited number of samples after PSM. In the multivariate analysis, before PSM, T and N stage, the level of EGFR, and neoadjuvant chemotherapy were independent risk factors affecting the OS of HAS and non-HAS patients. T stage, the level of CEA and EGFR and neoadjuvant chemotherapy were independent risk factors affecting the OS of HAS and nonHAS patients in the 1:1 propensity matching. The level of CEA was an independent risk factor that affected the OS of patients after radical surgery in 1:2 propensity matching. Although distant metastasis (M1) was a significant predictor of OS after PSM, we have less data on distant metastasis, it was not convincing.

Our study had several limitations. First, it was retrospective and enrolled patients in a single institutional cohort. Second, we did not include information about the patient's postoperative chemotherapy in our study. However, we usually decided whether to give chemotherapy to patients according to their postoperative pathological results. Lastly, the follow-up time was not long enough to assess long-term prognosis. Despite these limitations, a relatively large number of patients and rigorous statistical methods made our results convincing.

\section{Conclusion}

There was no statistically significant difference in the overall survival time between patients with HAS and nonHAS after radical surgery and adjuvant chemotherapy. Under the condition that patients with HAS could tolerate the surgery, the choice of surgery indications and methods were the same as that of non-HAS, radical surgery was the best choice for HAS patients.

\section{Supplementary information}

Supplementary information accompanies this paper at https://doi.org/10. 1186/s12885-020-07031-9.

\section{Additional file 1}

Additional file 2.

\begin{abstract}
Abbreviations
HAS: Hepatoid adenocarcinoma of the stotmach; non-HAS: Non-hepatoid adenocarcinoma of the stomach; OS: The overall survival time;

PSM: Propensity score matching; GC: Gastric carcinoma;

CEA: Carcinoembryonic antigen; CA199: Carbohydrate antigen 19-9;

MRI: Magnetic resonance imaging; CT: Computed tomography; AAT: Alpha-1

antitrypsin; ACT: Alpha-1 antichymotrypsin; IHC: Immunohistochemistry
\end{abstract}

\section{Acknowledgments}

Not applicate

\section{Authors'contributions}

Conceptualization and design: KZ, AQW. Data analysis and interpretation: KZ, AQW. Writing an original draft: KZ. Reviewed, methodology and edited this manuscript: AQW. Collected all samples: SA, JHC, KJ, QFH, XJ, XJW, JZ. Provide pathological information: ZWL. Conceptualization, review and financial support of the study: ZDB, JFJ. Final approval of the manuscript: all authors.

\section{Funding}

This study was supported by the National Science Foundation for Young Scientists of China (81802735), Beijing Youth Talent Plan (QML20191101) and Science Foundation of Peking University Cancer Hospital 2020-11.

These institutions did not play a role in study design, data collection, data analysis, data interpretation, or writing of the manuscript.

\section{Availability of data and materials}

The datasets used and/or analyzed during the current study are available by contacting kai zhou by email (zhoukai0615@pku.edu.cn) on a reasonable request.

Ethics approval and consent to participate

This research was approved by the Ethics Committee of the Peking University Cancer Hospital. Written informed consent was obtained from participating patients.

Consent for publication

Not applicable.

\section{Competing interests}

This study is no potential conflicts of interest.

\section{Author details}

${ }^{1}$ Department of Gastrointestinal Surgery, Key Laboratory of Carcinogenesis and Translational Research (Ministry of Education), Peking University Cancer Hospital \& Institute, No. 52 Fucheng Road, Haidian District, Beijing 100142,

China. ${ }^{2}$ Department of Gastrointestinal Surgery, Peking University Shenzhen Hospital, Shenzhen 518036, Guangdong, China. ${ }^{3}$ Department of Pathology,

Key Laboratory of Carcinogenesis and Translational Research (Ministry of Education), Peking University Cancer Hospital \& Institute, Beijing 100142,

China.

Received: 24 March 2020 Accepted: 3 June 2020

Published online: 17 July 2020

\section{References}

1. Wang A, Li Z, Wang Q, Bai Y, Ji X, Fu T, Ji K, Xue Y, Han T, Wu X, et al. Diagnostic value of negative enrichment and immune fluorescence in situ hybridization for intraperitoneal free cancer cells of gastric cancer. Chin J Cancer Res. 2019;31(6):945-54.

2. Torre LA, Bray F, Siegel RL, Ferlay J, Lortet-Tieulent J, Jemal A. Global cancer statistics, 2012. CA Cancer J Clin. 2015;65(2):87-108. 
3. Yang Z, Zeng H, Xia R, Liu Q, Sun K, Zheng R, Zhang S, Xia C, Li H, Liu S, et al. Annual cost of illness of stomach and esophageal cancer patients in urban and rural areas in China: a multi-center study. Chin J Cancer Res. 2018:30(4):439-48.

4. Geng X, Liu H, Lin T, Hu Y, Chen H, Zhao L, Mou T, Qi X, Yu J, Li G. Survival benefit of gastrectomy for gastric cancer with peritoneal carcinomatosis: a propensity score-matched analysis. Cancer Med. 2016;5(10):2781-91.

5. Jemal A, Bray F, Center MM, Ferlay J, Ward E, Forman D. Global cancer statistics. CA Cancer J Clin. 2011;61(2):69-90.

6. Chen W, Sun K, Zheng R, Zeng H, Zhang S, Xia C, Yang Z, Li H, Zou X, He J. Cancer incidence and mortality in China, 2014. Chin J Cancer Res. 2018; 30(1):1-12.

7. Wang Y, Sun L, Li Z, Gao J, Ge S, Zhang C, Yuan J, Wang X, Li J, Lu Z, et al. Hepatoid adenocarcinoma of the stomach: a unique subgroup with distinct clinicopathological and molecular features. Gastric Cancer. 2019;22(6):1 183-92.

8. Baek SK, Han SW, Oh DY, Im SA, Kim TY, Bang YJ. Clinicopathologic characteristics and treatment outcomes of hepatoid adenocarcinoma of the stomach, a rare but unique subtype of gastric cancer. BMC Gastroenterol. 2011;11:56.

9. Xiao C, Wu F, Jiang H, Teng L, Song F, Wang Q, Yang H. Hepatoid adenocarcinoma of the stomach: nine case reports and treatment outcomes. Oncol Lett. 2015;10(3):1605-9.

10. Yu C. Comment on: Hepatoid adenocarcinoma of the stomach: a unique subgroup with distinct clinicopathological and molecular features. Gastric Cancer. 2019; 1-10" by Wang et al. Gastric Cancer 2019.

11. Bourreille J, Metayer P, Sauger F, Matray F, Fondimare A. Existence of alpha feto protein during gastric-origin secondary cancer of the liver. Presse Med. 1970;78(28):1277-8.

12. Inagawa S, Shimazaki J, Hori M, Yoshimi F, Adachi S, Kawamoto T, Fukao K, Itabashi M. Hepatoid adenocarcinoma of the stomach. Gastric Cancer. 2001; 4(1):43-52.

13. Ishikura H, Fukasawa Y, Ogasawara K, Natori T, Tsukada Y, Aizawa M. An AFP-producing gastric carcinoma with features of hepatic differentiation. A case report. Cancer. 1985:56(4):840-8.

14. Trompetas V, Varsamidakis N, Frangia K, Polimeropoulos V, Kalokairinos E. Gastric hepatoid adenocarcinoma and familial investigation: does it always produce alpha-fetoprotein? Eur J Gastroenterol Hepatol. 2003;15(11):1241-4.

15. Zhou RU, Cai Y, Yang YI, Xiang J, Chen Z. Hepatoid adenocarcinoma of the stomach: a case report and review of the literature. Oncol Lett. 2015;9(5): 2126-8.

16. Soreide JA, Greve OJ, Gudlaugsson E, Storset S. Hepatoid adenocarcinoma of the stomach--proper identification and treatment remain a challenge. Scand J Gastroenterol. 2016;51(6):646-53.

17. Jalle T, Gerard C, Lada PE, Sagan C, Gournay J, Arnaud JP, Paineau J, Hamy A. Hepatoid adenocarcinoma of the stomach. A case report. Ann Chir. 2006; 131(3):213-5.

18. Qu BG, Bi WM, Qu BT, Qu T, Han XH, Wang H, Liu YX, Jia YG. PRISMAcompliant article: clinical characteristics and factors influencing prognosis of patients with Hepatoid adenocarcinoma of the stomach in China. Medicine (Baltimore). 2016;95(15):e3399.

19. Fakhruddin N, Bahmad HF, Aridi T, Yammine Y, Mahfouz R, Boulos F, Awada A, Farhat F. Hepatoid adenocarcinoma of the stomach: a challenging diagnostic and therapeutic disease through a case report and review of the literature. Front Med (Lausanne). 2017:4:164.

20. Zeng XY, Yin YP, Xiao H, Zhang P, He J, Liu WZ, Gao JB, Shuai XM, Wang $\mathrm{GB}, \mathrm{Wu} X \mathrm{X}$, et al. Clinicopathological characteristics and prognosis of Hepatoid adenocarcinoma of the stomach: evaluation of a pooled case series. Curr Med Sci. 2018;38(6):1054-61.

21. Zhang JF, Shi SS, Shao YF, Zhang HZ. Clinicopathological and prognostic features of hepatoid adenocarcinoma of the stomach. Chin Med J. 2011 124(10):1470-6.

22. Ishikura H, Kanda M, Ito M, Nosaka K, Mizuno K. Hepatoid adenocarcinoma: a distinctive histological subtype of alpha-fetoprotein-producing lung carcinoma. Virchows Arch A Pathol Anat Histopathol. 1990:417(1):73-80.

23. Akiyama S, Tamura G, Endoh Y, Fukushima N, Ichihara Y, Aizawa K, Kawata S, Motoyama T. Histogenesis of hepatoid adenocarcinoma of the stomach: molecular evidence of identical origin with coexistent tubular adenocarcinoma. Int J Cancer. 2003;106(4):510-5.

24. Fujii H, Ichikawa K, Takagaki T, Nakanishi Y, Ikegami M, Hirose S, Shimoda T. Genetic evolution of alpha fetoprotein producing gastric cancer. J Clin Pathol. 2003;56(12):942-9.
25. Sun X, Li Y, Dong M, Li W, Xing L. Hepatoid adenocarcinoma of the stomach: dual-time-point (18) F-FDG PET/CT findings. Jpn J Radiol. 2014; 32(12):721-4.

26. Yang J, Wang R, Zhang W, Zhuang W, Wang M, Tang C. Clinicopathological and prognostic characteristics of hepatoid adenocarcinoma of the stomach. Gastroenterol Res Pract. 2014;2014:140587.

27. Liu X, Sheng W, Wang Y. An analysis of clinicopathological features and prognosis by comparing hepatoid adenocarcinoma of the stomach with AFP-producing gastric cancer. J Surg Oncol. 2012;106(3):299-303.

28. Cheon SH, Rha SY, Jeung HC, Im CK, Kim SH, Kim HR, Ahn JB, Roh JK, Noh $\mathrm{SH}$, Chung HC. Survival benefit of combined curative resection of the stomach (D2 resection) and liver in gastric cancer patients with liver metastases. Ann Oncol. 2008;19(6):1146-53.

29. Lin CY, Yeh HC, Hsu CM, Lin WR, Chiu CT. Clinicopathologial features of gastric hepatoid adenocarcinoma. Biom J. 2015;38(1):65-9.

30. Chang YC, Nagasue N, Abe S, Kohno H, Kumar DD, Nakamura T. Alpha fetoprotein producing early gastric cancer with liver metastasis: report of three cases. Gut. 1991;32(5):542-5.

31. Liu X, Cheng Y, Sheng W, Lu H, Xu X, Xu Y, Long Z, Zhu H, Wang Y. Analysis of clinicopathologic features and prognostic factors in hepatoid adenocarcinoma of the stomach. Am J Surg Pathol. 2010;34(10):1465-71.

32. Galvez-Munoz E, Gallego-Plazas J, Gonzalez-Orozco V, Menarguez-Pina F, Ruiz-Macia JA, Morcillo MA. Hepatoid adenocarcinoma of the stomach - a different histology for not so different gastric adenocarcinoma: a case report. Int Semin Surg Oncol. 2009;6:13.

33. Kumashiro Y, Yao T, Aishima S, Hirahashi M, Nishiyama K, Yamada T, Takayanagi R, Tsuneyoshi M. Hepatoid adenocarcinoma of the stomach: histogenesis and progression in association with intestinal phenotype. Hum Pathol. 2007;38(6):857-63.

34. Augustin G, Jelincic Z, Tentor D, Majerovic M, Matosevic P. Hepatoid adenocarcinoma of the stomach: case report and short notes on immunohistochemical markers. Acta Gastroenterol Belg. 2009;72(2):253-6.

35. Giustozzi G, Goracci G, Bufalari A, Lauro A, Cirocchi R, Boselli C, Bartoli A, Monacelli M, Giansanti M, Moggi L. Hepatoid carcinoma of the stomach: is it still an unusual anatomo-clinical entity? Six cases-report. J Exp Clin Cancer Res. 1999;18(4):571-3.

36. Liu XM, Chen GQ, Li SL, Zai TS. Hepatoid adenocarcinoma of the stomach: a case report and literature review. Exp Ther Med. 2015;9(6):2133-6.

37. Velut G, Mary F, Wind P, Aparicio T. Adjuvant chemotherapy by FOLFOX for gastric hepatoid adenocarcinoma. Dig Liver Dis. 2014;46(12):1135-6.

\section{Publisher's Note}

Springer Nature remains neutral with regard to jurisdictional claims in published maps and institutional affiliations.

Ready to submit your research? Choose BMC and benefit from:

- fast, convenient online submission

- thorough peer review by experienced researchers in your field

- rapid publication on acceptance

- support for research data, including large and complex data types

- gold Open Access which fosters wider collaboration and increased citations

- maximum visibility for your research: over $100 \mathrm{M}$ website views per year

At BMC, research is always in progress.

Learn more biomedcentral.com/submissions 